\title{
ÉTICA EM CONTABILIDADE: UM ESTUDO SOBRE A PERCEPÇÃO DOS DISCENTES ACERCA DA ÉTICA PROFISSIONAL ${ }^{1}$
}

\section{ACCOUNTING ETHICS: A STUDY ABOUT THE STUDENTS'S PERCEPTION ON PROFESSIONAL ETHICS}

\section{ÉTICA EN CONTABILIDAD: UN ESTUDIO SOBRE LA PERCEPCIÓN DE LOS ESTUDIANTES ACERCA DE LA ÉTICA PROFESIONAL}

Maria Eduarda Barbosa Lima, Graduada em Ciências Contábeis. Faculdade de Ciências da Administração do Limoeiro - FACAL. Endereço Profissional: Av. Jerônimo Heráclio, $n^{\circ} 81$, Centro, Limoeiro-PE - CEP: 55700-970, E-mail: eduardalima92@hotmail.com

Rodrigo Vicente dos Prazeres, Mestrando em Ciências Contábeis - PPGCC. Universidade Federal de Pernambuco - UFPE. Endereço Profissional: Av. Prof. Moraes Rego, 1235 Cidade Universitária, Recife - PE - CEP: 50670-901, E-mail: rodrigovprazeres@ gmail.com

João Gabriel Nascimento de Araújo, Mestrando em Ciências Contábeis - PPGCC. Universidade Federal de Pernambuco - UFPE. Endereço Profissional: Av. Prof. Moraes Rego, 1235 - Cidade Universitária, Recife - PE - CEP: 50670-901, E-mail: j_gabrie190@hotmail.com

Juliana Gonçalves de Araújo, Mestranda em Ciências Contábeis - PPGCC. Universidade Federal de Pernambuco - UFPE. Endereço Profissional: Av. Prof. Moraes Rego, 1235 Cidade Universitária, Recife - PE - CEP: 50670-901, E-mail: juhliana.araujo@gmail.com

\section{RESUMO}

Esta pesquisa teve como objetivo geral analisar a percepção dos alunos do Curso de Ciências Contábeis no que diz respeito à aplicação de conceitos éticos na profissão contábil, e, ao processo de ensino da ética aplicada a Contabilidade. A metodologia de pesquisa constituiu na aplicação de um questionário com escala Likert de 5 pontos onde solicitou-se a cada respondente justificar sua resposta. O questionário aplicado foi dividido em três blocos, sendo eles: o perfil dos discentes; a percepção dos respondentes sobre a ética profissional; e, a percepção dos discentes sobre o processo de ensino da ética profissional em contabilidade. A população da pesquisa correspondeu aos alunos do $5^{\circ}$ ao $8^{\circ}$ semestre do curso de Ciências Contábeis da Faculdade de Ciências Aplicadas de Limoeiro (FACAL). Na análise dos dados utilizaram-se duas técnicas, a estatística descritiva, que foi utilizada para análise das questões que buscava verificar a concordância dos participantes em cada um dos quesitos apresentados, e, a análise de conteúdo, que foi utilizada para examinar as justificativas dadas pelos respondentes de acordo com seu grau de concordância dos quesitos. Como resultado, encontrou-se que a ética é considerada fator de grande importância no ambiente profissional,

\footnotetext{
${ }^{1}$ Artigo submetido em 11/07/2014, revisado em 22/07/2014, aceito em 20/08/2014 e divulgado em 01/12/2014 pelo Editor João Carlos Hipólito Bernardes do Nascimento, após double blind review.
}

GєCont, v. 1, n. 2, Floriano-PI, Jan-Jun. 2014. 
mas que é um procedimento de difícil aplicação. Já o processo de ensino é considerado pelos respondentes como um meio para o alcance de uma maior percepção crítica dos discentes.

Palavras-Chave: Ética; Percepção dos Discentes; Profissão Contábil.

\begin{abstract}
This research aimed to analyze the students' perception of Accounting students regarding to the application of ethical concepts in the accounting profession, and the process of teaching. The research methodology consisted in the application of a 5-point Liket scale survey and was asked to the respondents to justify the answers. The survey consisted in three blocks, namely: profile of the students; perception of the respondents about professional ethics; and the perception of the students about the teaching of ethics in accounting. The research population corresponded to students from 5th to 8th semester of Accounting from FACAL. In the data analysis two techniques were used, descriptive statistics, which was used to analize and verify the agreement of the participants in each one the questions presented, and the content analysis, which was used to examine the reasons given by the respondents according to their degree of agreement. As results, was found that ethics is considered very important in the professional environment, but it is difficult to implement. Regading the teaching process, the answers of the respondents shown that it helps the students to achieve a greater critical awareness.
\end{abstract}

Keywords: Ethics; Perception of Students; Accounting Profession.

\title{
RESUMEN
}

Esta investigación tiene como principal objetivo analizar la percepción del Curso de Contabilidad de los estudiantes con respecto a la aplicación de los conceptos de ética en la profesión contable, y el proceso de la enseñanza de la ética aplicada a la contabilidad. La metodología de la investigación consistió en la aplicación de un cuestionario con escala Likert de 5 puntos donde se pedía a cada encuestado para justificar su respuesta. El cuestionario se divide en tres bloques, a saber: el perfil de los estudiantes; la percepción de los encuestados acerca de la ética profesional; y la percepción de los estudiantes sobre la enseñanza de la ética profesional en contabilidad. La población de la investigación correspondió a estudiantes de $5^{\circ}$ a 8 semestre de Contabilidad de la FACAL. En el análisis de los datos se utilizaron dos técnicas estadísticas descriptivas, que se utilizó para el análisis de los asuntos buscados para verificar el acuerdo de los participantes en cada una de las preguntas presentadas, y el análisis de contenido, que se utilizó para examinar las causas invocadas los encuestados en función de su grado de acuerdo de las preguntas. Como resultado, se encontró que la ética se considera muy importante en el factor entorno profesional, pero es un procedimiento difícil de implementar. Haga que el proceso de enseñanza es considerada por los encuestados como un medio para lograr una mayor conciencia crítica de los estudiantes.

Palabras clave: Ética; Percepción de Estudiantes; Profesión contable.

\section{INTRODUÇÃO}

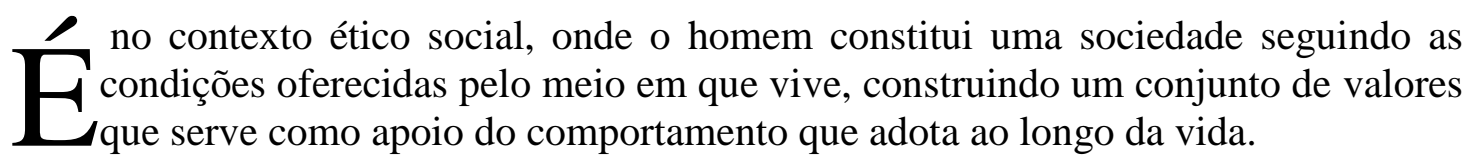

GєCont, v. 1, n. 2, Floriano-PI, Jul-Dez. 2014. 
Dentre os vários contextos onde a ética está inserida, o entendimento de como a ética se relaciona ao ambiente profissional é de extrema importância para a sociedade, mais especificamente quanto aos profissionais da área contábil, dada a demanda coletiva pela conduta que honestidade e transparência deste tipo de profissional.

Da mesma forma, o mesmo padrão de conduta ético-profissional será demandando dos futuros profissionais para que estes exerçam suas atividades dentro do que é considerado como eticamente correto.

Acerca deste posicionamento, Lisboa (1997, p. 11) deixa bem claro a importância da ética nas profissões:

Não há sociedade que progrida com firmeza por muito tempo, que se mantenha politicamente consistente, que ofereça bem estar social a seus membros, nem profissão que se imponha pelo produto de seu trabalho que se faça reconhecer por seus próprios méritos, sem que esteja a Ética a servir de cimento a fortalecer sua estrutura, de amarras a suportar as tempestades, de alicerce a suportar o crescimento e de raízes e seiva para garantir a sobrevivência dessa sociedade ou dessa profissão. Sem Ética, a sociedade não se estrutura de forma permanente; e uma profissão também não.

Configurada a importância da ética no contexto da profissão contábil, este estudo busca avançar no sentido da compreensão da percepção dos profissionais em formação, na busca pelo entendimento sobre como os princípios éticos relacionados à profissão contábil são entendidos pelos discentes do curso de graduação em Ciências Contábeis.

Dessa forma, procura-se entender a percepção que os discentes possuem sobre o ensino da ética durante o curso de graduação, bem como os possíveis reflexos que o processo de ensino e aprendizagem da ética profissional ocasionará quando do exercício profissional na área contábil.

Assim, busca-se um aprofundamento acerca dessa temática, no intuito de entender se o processo de ensino e aprendizagem da Ética Profissional em Contabilidade é capaz de contribuir para o bom desempenho dos profissionais contábeis.

Uma boa formação ética pode ajudar os futuros profissionais a atuarem na área contábil de forma honesta e transparente. A atitude ética tornou-se uma ferramenta fundamental, a qual todo profissional precisa manter para que tenha uma imagem positiva relacionada ao serviço que presta a sociedade (BORGES; MEDEIROS, 2007).

Conforme Lopes de Sá (2001, pg. 196):

A ausência de conhecimento caracteriza a incompetência, o mau uso, a
desonestidade, a omissão, o relaxamento ou negligência. O profissional
incompetente, para realizar uma tarefa, tende a cometer erros que prejudicam seus
clientes. Aquele que utiliza maldosamente sua competência visa beneficiar alguém e
prejudicar terceiros. O omisso pode causar danos irreparáveis e também acaba por
ser prejudicial, quer o faça por intenção ou não. Em todos os casos há sempre lesão
ao bem de terceiros e à obra realizada, em virtude de infrações contra o dever ético
de competência.

Assim, evidenciada a relevância da ética no contexto profissional, se faz importante que os estudantes entendam o papel da ética, posto que o aprendizado adquirido no meio acadêmico tem por finalidade influenciar no direcionamento da postura ética dos futuros profissionais, dos quais serão demandadas uma postura profissional ética.

Diante do exposto, apresenta-se a seguinte pergunta de pesquisa que orienta este trabalho: Qual a percepção dos alunos do Curso de Ciências Contábeis sobre a aplicação dos 
conceitos éticos na profissão contábil, bem como sobre o processo de ensino da Ética aplicada à Contabilidade?

O estudo é relevante posto que se demanda um comportamento ético dos profissionais em contabilidade, dado que o correto comportamento ético, além de outros fatores é influenciado pelo ensino da ética profissional voltado para a profissão contábil durante a formação de nível superior dos discentes.

Assim, nasce a necessidade de se identificar a percepção dos alunos do curso de graduação em contabilidade quanto à aplicação dos conceitos éticos aprendidos durante o curso de graduação, bem como sua percepção sobre as qualidades e deficiências do ensino da ética profissional, na busca de um maior aprofundamento sobre como a formação de contadores influencia posturas éticas ou antiéticas enquanto profissionais.

Sendo assim, este trabalho busca contribuir com um maior entendimento sobre como a formação acadêmica, relativamente à Ética Profissional dos futuros profissionais da área contábil pode contribuir para uma atuação profissional mais transparente.

O trabalho está estruturado em cinco seções. Após a presente introdução, encontra-se a fundamentação teórica, onde são abordados os tópicos "a origem da ética e sua evolução", "profissão contábil e a ética", "processo de ensino e aprendizagem da ética na contabilidade" e "estudos anteriores". Já a terceira seção trata da metodologia utilizada para o desenvolvimento do estudo e a quarta seção apresenta os resultados alcançados, sendo seguida pela última seção que apresenta as conclusões do estudo.

\section{FUNDAMENTAÇÃO TEÓRICA}

\subsection{Origem da Ética e Sua Evolução}

A palavra grega ethos (ética) e a palavra latina, mores (moral), ambas significam hábitos e costumes. A moral sendo sinônimo de ética terá assim um conjunto de normas, em determinado espaço, sendo aprovado para o comportamento dos homens. A ética leva a ideia do todo moral, natural do comportamento humano, que são expressas através dos princípios do pensamento normal e saudável (LISBOA, 1997).

Quando se fala sobre Ética no cotidiano, passa-se a refletir sobre atitudes, comportamentos, valores e fundamentos de nossas vidas. Trata-se de criar ações, reflexões e discussões sobre seus significados e sua importância para o desenvolvimento dos seres humanos e suas relações com o mundo.

Conforme Lisboa (1997, p. 54):

A proteção dos valores éticos deve representar uma decisão que a sociedade precisa tomar em seu conjunto e jamais uma imposição de cima, ou seja, para que os valores éticos sejam preservados é necessário que a maior parte de seus participantes assim o deseje, que seja educada para tal; que aceite e, mais importante, que exercite essa proteção a todo instante.

Sendo de fundamental importância para a vida humana, a ética está continuadamente junto a todos. "A ética é daquelas coisas que todo mundo sabe o que são, mas que não são fáceis de explicar, quando alguém pergunta" (VALLS, 1994, p.7).

A ética tem como finalidade estudar o comportamento do homem, estabelecendo níveis de convivência que sejam aceitáveis entre a sociedade e os indivíduos que a integram (LISBOA, 1997).

GєCont, v. 1, n. 2, Floriano-PI, Jul-Dez. 2014. 
Neste sentido é apontado por Lisboa (1997, p. 130):

Não se acredita que qualquer pessoa é completamente ética todo o tempo. Tais pessoas, se existirem, excedem tudo o que se conhece sobre a personalidade humana. Como profissionais e cidadãos, precisa-se agir tão eticamente quanto possível para causar um mal mínimo e promover o bem-estar social.

No que diz respeito à utilização da ética no contexto profissional, Lisboa (1997) entende que esta acaba por requerer certo nível de conhecimento em relação aos assuntos técnicos da profissão, devendo assim agir com respeito aos seus colegas de profissão.

\subsection{A Profissão Contábil e a Ética}

De acordo com Assaf Neto e Araújo (2004, pág. 13)

A contabilidade é conceituada como um sistema de informação capaz de orientar os donos ou acionistas de uma empresa a tomarem decisões apoiados em números que idealizem a situação financeira e patrimonial do seu negócio. Nesse momento, o conceito de patrimônio é o capital investido no negócio e sua evolução durante certo período.

No exercício da profissão, o Contador terá contato com diversas áreas da empresa como a patrimonial e econômica, tendo assim, acesso a informações privilegiadas as quais serão fornecidas para a tomada das decisões, sendo indispensável o sigilo destas informações e uma postura ética para que se tenha um bom desempenho profissional e um contínuo cargo de confiança na empresa.

Conforme Lopes de Sá (2001, pág. 131):

O ser que se dedica à Contabilidade possui deveres para com a regularidade do emprego racional da riqueza nas empresas, nas instituições diversas, assim como perante o ensaio, a pesquisa, a difusão cultural e educacional, o mercado, a sociedade e também na produção de provas e opiniões sobre comportamentos do patrimônio.

O trabalho é um compromisso social, mas além de tudo, uma fonte de vida, uma forma de realização de quem o faz empregar honestidade e responsabilidade na realização de suas tarefas como guia de todas as suas práticas profissionais. Ainda segundo Sá (2001), a profissão contábil destaca-se por seu papel de proteção à vida da riqueza das células sociais e pela capacidade de produzir informes qualificados sobre o comportamento patrimonial.

O papel do profissional contábil é proporcionar a eficácia na utilização da riqueza. Sendo que é de extrema importância ter responsabilidade e um comportamento adequado para ter como resultado, o bom desempenho de sua atividade. Conforme Marion (2009, pág. 28), "a contabilidade é o instrumento que fornece o máximo de informações úteis para a tomada de decisões dentro e fora da empresa".

Como meio de se manter os padrões de conduta da atividade profissional, é necessário que se alcance um bom renome junto a população, sendo, portanto, estabelecidas algumas normas, como por exemplo, os códigos de ética que devem sempre ser levados em consideração quando diz respeito a tomada de decisões que envolvam o comportamento ético.

Apresentada a relevância da contabilidade, tendo em vista o valor do ser ético ao desempenhar a profissão contábil, será realizada a seguir uma associação da ética ao exercício das atividades contábeis. A ética requer certo nível de conhecimento em relação aos assuntos técnicos da profissão ora desenvolvida, devendo agir com respeito aos colegas de profissão, assim como também aos seus contratantes e associados, enfim todos os usuários das informações contábeis (ANTONOVZ et al, 2010). 
Neste contexto, o profissional acaba se destacando não apenas pela elaboração e interpretação das informações contábeis, mas também pela atuação ética e transparente na realização de suas atividades.

Lopes de Sá (2001, p. 138) afirma o seguinte:

O valor profissional deve acompanhar- se de um valor ético para que assim possa existir uma integral imagem de qualidade. Não se pode construir um conceito pleno sem que se pratique uma conduta que seja de forma qualificada.

No entanto, mesmo que o conhecimento seja uma forma de contribuição para o desenvolvimento do profissional, sem ética e transparência nas suas atividades, este profissional não vai obter grandes resultados, pois ter conhecimento não significa ser ético, não necessariamente. A profissão de um indivíduo, quando bem executada, permite que ele receba em troca, a admiração e confiança de outras pessoas, contribuindo assim com uma melhoria da sua imagem (ANTONOVZ et al., 2010).

O contador tem uma vasta responsabilidade sobre as tarefas que desempenha. Por isso, é necessário a ele ter uma consciência profissional bem construída e que, associada às virtudes que possui, possa conduzir seu trabalho de modo ético e moralmente baseado (MORAES; SILVA; CARVALHO, 2010).

Lisboa (1997, pág. 130) relata o seguinte: "para adquirir uma consciência ética, pois é preciso: Acreditar em valores; ter a capacidade de refletir; e possuir senso de comunidade".

Nesse aspecto, o profissional contábil deve defender abertamente os princípios e os valores éticos aplicáveis a sua profissão, de tal modo a causar uma imagem construtiva e que no desenvolver de suas atividades profissionais, possa ser visto como exemplo para uma nova geração de profissionais.

\subsection{Processo de Ensino e Aprendizagem da Ética na Contabilidade}

O estudo da Ética é relevante no que diz respeito à necessidade das pessoas orientarem seu comportamento para agirem de acordo com as mudanças que ocorrem diariamente na vida em sociedade (COVA, 2005; MORAES; SILVA; CARVALHO, 2010).

Segundo Marion (2001 p. 14) "a educação para os futuros contadores deveria produzir profissionais que tivessem amplo conjunto de habilidades e conhecimentos". Por sua vez, o professor compreendendo quais são os interesses e necessidades dos seus alunos podem criar condições de ensino que atendam às características de aprendizagem dos estudantes e que garantam a eficácia do seu papel de educador. Contudo, a aprendizagem é um procedimento contínuo que ocorre durante toda nossa vida, basta termos força de vontade para buscá-la.

Freire (1987) relata sobre o processo de ensino afirmando que ensinar inexiste sem aprender e vice-versa. Ainda segundo Freire (1987), foi aprendendo socialmente, que, historicamente, mulheres e homens descobriram que era possível ensinar e foi assim, socialmente aprendendo, que ao longo dos tempos mulheres e homens perceberam que era possível e preciso trabalhar maneiras, caminhos, métodos de ensinar. Aprender precedeu ensinar ou, em outras palavras, ensinar se diluía na experiência realmente fundante de aprender.

A relação entre ensino e aprendizagem não é apenas a transferência do professor que ensina para o aluno que aprende, mas sim, uma relação que tem que haver reciprocidade. Conforme Mendes (2000), é preciso inverter a posição até então considerada tradicional, aquela em que o aluno fica numa situação passiva e o professor na ativa, no sentido de transmitir conhecimentos e apontar erros cometidos. O aluno é que deve ser agente ativo do 
processo e o professor, antes apenas um agente de mudança, deve ser o facilitador do processo de ensino e aprendizagem. Cabe, então, ao professor a iniciativa para esta mudança.

Tendo em vista o papel do docente, em trazer à tona a capacidade crítica do discente, fazer com que ele não apenas execute suas atividades, mas, seja capaz de expor sua opinião e, sobretudo, propor melhorias.

De acordo com Santos (2003), a arte de ensinar consiste em o educador saber escolher a técnica e os recursos mais adequados ao seu público. Neste aspecto, cabe ao educador perceber que os alunos são diferentes, inclusive na própria forma de captação de sua mensagem. Por exemplo, existem alunos mais auditivos, outros mais visuais, outros mais reflexivos, ou seja, são estimulados de diferentes formas para o aprendizado.

A questão ensino e aprendizagem devem ser ressaltadas de forma contínua, isto é, deve estar sempre procurando formas de ensino alternativas que estimulem e impulsionem o discente ao aprendizado, para que ele se sinta motivado para o exercício prático da profissão que escolheu.

\subsection{Estudos Anteriores}

A ética em contabilidade tem sido discutida em vários estudos ao longo dos últimos anos, dentre os quais, pode-se destacar os trabalhos de Cunha (2005), Cova (2005), Borges e Medeiros (2007), Antonovz et al (2010), Moraes, Silva e Carvalho (2010), Lustosa et al (2012) e Sallaberry e Sallaberry (2012).

No Quadro 1, está apresentado um resumo com informações sobre esses estudos anteriores: seus autores, objetivos e principais resultados.

Quadro 1-Resumo dos estudos anteriores.

\begin{tabular}{|c|c|c|}
\hline Autores & Objetivo & Resultados \\
\hline Cunha (2005) & $\begin{array}{l}\text { Discutir a ética e a contabilidade inseridas } \\
\text { no espaço público. }\end{array}$ & $\begin{array}{l}\text { Instigar o debate, sob o viés sociológico, da } \\
\text { ética e da contabilidade. }\end{array}$ \\
\hline Cova (2005) & $\begin{array}{l}\text { Demonstrar a importância que a } \\
\text { Contabilidade possui para o pleno } \\
\text { funcionamento dos mercados financeiros, } \\
\text { e, consequentemente, para a correta } \\
\text { alocação dos recursos na sociedade, de tal } \\
\text { forma a garantir a eficiência do sistema } \\
\text { econômico. }\end{array}$ & $\begin{array}{l}\text { Inferiu que o ambiente de mercado é bastante } \\
\text { influenciado pela ação cotidiana de seus atores, } \\
\text { no que concerne aos princípios éticos que os } \\
\text { norteiam. }\end{array}$ \\
\hline $\begin{array}{l}\text { Borges e } \\
\text { Medeiros } \\
(2007)\end{array}$ & $\begin{array}{l}\text { Conhecer os preceitos éticos presentes na } \\
\text { atuação profissional dos contabilistas. }\end{array}$ & $\begin{array}{l}\text { Evidenciou-se que os profissionais utilizam os } \\
\text { elementos mínimos que devem constar num } \\
\text { código de ética. }\end{array}$ \\
\hline $\begin{array}{l}\text { Antonovz et } \\
\text { al (2010) }\end{array}$ & $\begin{array}{l}\text { Verificar a percepção ética dos } \\
\text { contadores, mapeada por evidências de } \\
\text { profissionais e estudantes de } \\
\text { contabilidade sob a perspectiva de gênero. }\end{array}$ & $\begin{array}{l}\text { Demonstrou um perfil mais ético por parte das } \\
\text { mulheres. }\end{array}$ \\
\hline $\begin{array}{l}\text { Moraes, Silva } \\
\text { e Carvalho } \\
(2010)\end{array}$ & $\begin{array}{l}\text { Analisar a atitude de estudantes da área } \\
\text { contábil quando confrontados com } \\
\text { questões antiéticas. }\end{array}$ & $\begin{array}{l}\text { Observou que o gênero, idade e tempo de } \\
\text { trabalho influenciaram o posicionamento ético } \\
\text { dos estudantes de contabilidade entrevistados } \\
\text { nesta pesquisa, em relação aos dilemas éticos } \\
\text { apresentados. }\end{array}$ \\
\hline $\begin{array}{l}\text { Lustosa et al } \\
(2012)\end{array}$ & $\begin{array}{l}\text { Avaliar o nível moral dos contadores } \\
\text { brasileiros, com base no julgamento } \\
\text { desses sobre decisões que envolvem } \\
\text { conflitos éticos. }\end{array}$ & $\begin{array}{l}\text { Revelam que o julgamento moral dos } \\
\text { respondentes é diretamente relacionado com o } \\
\text { que eles preveem para o próprio } \\
\text { comportamento. }\end{array}$ \\
\hline
\end{tabular}

GєCont, v. 1, n. 2, Floriano-PI, Jul-Dez. 2014. 


\begin{tabular}{|l|l|l|}
\hline $\begin{array}{l}\text { Sallaberry e e } \\
\text { Sallaberry } \\
(2012)\end{array}$ & $\begin{array}{l}\text { Identificar os aspectos da contabilidade } \\
\text { voltados às ações de inclusão social, com } \\
\text { foco na acessibilidade das pessoas com } \\
\text { necessidade especial. }\end{array}$ & $\begin{array}{l}\text { Apesar de não constar a expressa obrigação aos } \\
\text { profissionais contábeis de desenvolver políticas } \\
\text { de inclusão social já se percebe na prática } \\
\text { algumas ações afirmativas no âmbito dos } \\
\text { Conselhos de Contabilidade, inclusive com } \\
\text { ações voltadas à acessibilidade das instalações } \\
\text { e a contratação de pessoas deficientes. }\end{array}$ \\
\hline
\end{tabular}

Fonte: Elaboração própria

Este estudo se diferencia em relação aos demais uma vez que se propõe a analisar a ética tanto sob a perspectiva profissional quanto em seu processo de ensino.

\section{METODOLOGIA}

A presente pesquisa teve por objetivo analisar a percepção dos alunos do curso de Ciências Contábeis quanto ao processo de ensino e aprendizagem da ética aplicada a contabilidade. Para tanto, optou-se por uma estratégia de pesquisa de cunho qualitativo e de caráter exploratório. A princípio foram realizadas pesquisas sobre a origem e evolução da ética e sobre a metodologia utilizada no processo de ensino da ética na contabilidade.

Por conseguinte, foi elaborado um questionário com o objetivo de identificar a percepção dos alunos do curso de Ciências Contábeis acerca da aplicação dos conceitos de ética profissional, bem como sobre o processo de ensino e aprendizagem da ética na contabilidade. O questionário foi estruturado em três blocos: o primeiro relativo ao perfil dos discentes, o segundo relativo à aplicação dos conceitos éticos no ambiente profissional e o terceiro relativo ao processo de ensino da ética na Contabilidade.

Os questionários elaborados a partir destas etapas foram estruturados com base na escala Likert de 5 pontos, em que o ponto 1 indicava "discordo totalmente" e o ponto 5 indicava "concordo totalmente". Cada questionário apresentava a oportunidade dos respondentes descreverem a justificativa pelo grau de concordância.

A população de pesquisa correspondeu aos alunos do $5^{\circ}$ ao $8^{\circ}$ semestre do curso de Ciências Contábeis da Faculdade de Ciências Aplicadas de Limoeiro- FACAL. A escolha por esta população se deu devido a atual grade de disciplinas do curso, que oferece a disciplina de Ética Geral e Profissional em Contabilidade a partir do quinto semestre.

Sendo assim, o período de coleta de dados ocorreu na última semana do mês de maio de 2014, período este em que a disciplina de Ética Geral e Profissional em Contabilidade já havia sido encerrada, colocando assim os alunos do quinto semestre em condições de responder o questionário, tornando-os assim parte da população de pesquisa.

Dessa forma, a população de pesquisa compreendeu todos os alunos dos semestres acima citados, totalizando 52 alunos, sendo reduzida a quantidade de alunos matriculados neste semestre letivo e, consequentemente, dos respondentes, uma limitação deste estudo.

Após a aplicação dos questionários foram excluídos aqueles onde os respondentes não responderam todas as perguntas, totalizando dessa forma uma amostra de 26 questionários analisados por essa pesquisa.

Quanto ao tratamento dos dados coletados através do questionário, para sua análise foram utilizadas duas técnicas: a estatística descritiva e a análise de conteúdo. 
A estatística descritiva foi utilizada para análise das questões que buscava averiguar a concordância dos participantes em cada um dos quesitos apresentados.

No que se refere à técnica de análise de conteúdo, esta foi utilizada para examinar as justificativas dadas pelos respondentes de acordo com seu grau de concordância dos quesitos, buscando identificar os pontos convergentes e divergentes entre as declarações dadas nas justificativas dos questionamentos, com a finalidade de identificar um padrão sobre a percepção dos respondentes.

\section{ANÁLISE DOS DADOS}

\subsection{Análise do Perfil dos Respondentes}

Para que fosse possível fazer uma análise do perfil dos respondentes foram dispostas 3 questões sobre idade, gênero, e semestre atual do discente.

Quanto ao gênero, observou-se que a amostra foi formada predominantemente pelo gênero feminino, correspondendo a 14 mulheres (54\%). A idade dos respondentes foi segregada em intervalos, sendo eles: entre 18-22 anos, correspondendo a $15 \%$ (4 alunos) do total de respondentes; entre 23-26 anos representando 19\% (5 alunos); entre 27-30 anos, indicando um percentual de 27\% (7 alunos); e acima de 31 anos, apontando para um percentual de $31 \%$ (8 alunos). Resta ainda salientar, que do total de respondentes, 2 alunos não responderam esta questão, o que representa um percentual de $8 \%$ do total de questionários respondidos.

A última questão, referente ao semestre atual de cada discente foi visto que 4 respondentes (36\%) são alunos do $5^{\circ}$ semestre; $57 \%$ (8 alunos) são do $6^{\circ}$ semestre; 8 discentes (50\%) pertencem ao $7^{\circ}$ semestre; e, 6 alunos (54\%) são alunos do $8^{\circ}$ semestre, com um percentual de $50 \%$ de alunos respondentes, tendo em vista um total de 52 alunos do $5^{\circ}$ ao $8^{\circ}$ período.

Portanto, é visto que, a maioria dos respondentes são mulheres, a maior parte deles tem acima de 27 anos, o que indica que o curso é feito por pessoas mais experientes e que o sexto e sétimo semestres tem maior participação nas respostas.

\subsection{Percepção dos Respondentes sobre a Ética Profissional}

O segundo bloco do questionário buscou explorar a percepção dos respondentes acerca da Ética Geral e Profissional em Contabilidade. Para melhor apresentação do objetivo proposto neste bloco, o primeiro questionamento é apresentado da seguinte maneira: " $O$ entendimento de como a Ética se relaciona ao ambiente profissional é de extrema importância, você acha que a Ética é uma importante ferramenta para um bom desempenho profissional?".

Esta questão mostrou que não houve discordância deste questionamento, sendo que 92\% (24 respondentes) concordaram totalmente com o questionamento, e apenas $8 \%$ dos respondentes (2) concordaram parcialmente.

Ficando assim evidente que os respondentes acreditam que é de grande importância a aplicabilidade da ética no ambiente profissional, para que se possa transmitir mais segurança aos usuários da contabilidade. Por conseguinte, as justificativas de alguns discentes confirmaram que, "um profissional sem ética, é um profissional sem cultura e conhecimento" e que "a ética deve ser usada no nosso cotidiano, em especial no trabalho, em se tratando de 
vários clientes, devemos respeitá-los e tratá-los como indivíduo particular, com ética e respeito".

O segundo questionamento teve como centro a opinião dos respondentes acerca da aplicação dos princípios éticos na profissão contábil. Desta forma, levantou-se o seguinte questionamento: "Você considera que a aplicação dos princípios éticos na profissão contábil são de fácil aplicação?"

A maioria com um percentual de 54\% (14 respondentes) concordaram parcialmente; $15 \%$ (4 respondentes) concordaram totalmente; apenas 4\% (1) não discordou nem concordou; em sequência, 5 respondentes representando um percentual de $19 \%$ discordaram parcialmente; e, apenas $8 \%$ ( 2 respondentes) discordaram totalmente.

No entanto, um dos respondentes ao discordar totalmente afirmou, "está cada vez mais difícil agirmos dentro dos princípios éticos, isso não quer dizer que todos os profissionais estejam se corrompendo, uma vez que agimos de acordo com nossos preceitos". Posteriormente, outro respondente que concordou parcialmente com a afirmação justificou, "a ética muitas vezes é ignorada, pois muitos profissionais passam por cima dela por causa de dinheiro e/ou para não perder o cliente."

Contudo, pode-se concluir, diante da percepção dos discentes que a aplicação dos conceitos éticos é afetada, sobretudo, por interesses financeiros.

O terceiro questionamento foi acerca do Código de Ética Profissional do Contador, onde foi questionado o seguinte: "Quanto ao Código de Ética da Profissão Contábil, você o considera suficiente para o exercício ético da profissão contábil? Em caso de concordância, justifique quais qualidades você considera, em caso de discordância, justifique quais deficiências você considera.

Diante do questionamento, os respondentes, em sua maioria, afirmaram concordar com a assertiva, representando um percentual de 38\% (10); e, $19 \%$ (5 respondentes) concordaram parcialmente; não houve discordância total; mas, totalizando um percentual de 23\% (6 respondentes)discordaram parcialmente; e, 5 respondentes, representando um percentual de $19 \%$, não concordaram nem discordaram.

O código de ética serve, sobretudo, como meio orientador de conduta ética do profissional contábil, pois este deverá sempre levar em consideração a questão ética no decorrer do exercício profissional. Neste contexto, um dos respondentes que concordou totalmente afirmou: "o Código de ética é perfeito".

Por conseguinte, um dos respondentes que discordou parcialmente de acordo com a suficiência do código de ética na profissão contábil afirmou: "a ética apesar de ser ensinada não pode ser aplicada por todos, pois caráter e personalidade, cada um tem o seu".

Diante do exposto, pode-se afirmar que, para os participantes da pesquisa, o homem é afetado por outras condições, mas que alguns veem limitações na aplicabilidade do código de ética, enquanto outros o acham perfeito, no entanto, eles não nos dão maiores informações, o que acaba limitando a capacidade crítica dos respondentes.

A última questão deste bloco se referiu à facilidade do entendimento dos conceitos do código de ética da profissão contábil, o questionamento se apresentou da seguinte forma: Você considera que a aplicação dos conceitos do código de ética do profissional contábil são de fácil entendimento?

Os respondentes, em sua maioria, concordaram parcialmente com um percentual de $38 \%$ (10 respondentes); enquanto com um percentual de 15\% (4 respondentes) concordaram 
totalmente; não houve discordância total; logo, cerca de $31 \%$ (8 respondentes) discordaram parcialmente; e, cerca de $15 \%$ (4) não concordaram nem discordaram com a alegação.

O código de ética vem definir os padrões de comportamento procurando minimizar qualquer tipo de insegurança, tornando-o assim mais claro possível para sua fácil aplicabilidade ao exercer a profissão contábil.

A justificativa dos discentes que afirmaram concordar parcialmente evidenciou que, "todo contador deve conhecer o código de ética, pois o mesmo está acessível a todos". Porém, de acordo com um dos respondentes que discordou parcialmente afirmou-se o seguinte: "a teoria é bem diferente da prática, saber tudo sobre o código de ética, não quer dizer que irá por em prática". Porém, percebe-se de acordo com os respondentes, que o código de ética tem suas imperfeições dificultando seu entendimento e, posteriormente, sua aplicabilidade, precisando ser ainda muito melhorado.

A partir das colocações acima evidenciadas, pode-se concluir que, diante da percepção dos discentes, a ética é considerada fator de grande importância no ambiente profissional, mas também encontram limitações na aplicação dos princípios do código de ética, sobretudo, porque os respondentes não entendem a funcionalidade de todos os princípios, pois a aplicação da ética depende muito do interesse pessoal na situação analisada.

\subsection{Percepção dos respondentes sobre o processo de ensino da Ética em Contabilidade}

O terceiro e último bloco deste questionário teve como intuito saber como o processo de ensino contribui para uma melhor percepção e análise crítica da ética aplicada a profissão contábil.

Sendo assim, o primeiro questionamento foi expressado da seguinte forma: Você considera que o processo de ensino e aprendizagem pode resultar em reflexos positivos no exercício da profissão contábil?

Os respondentes, em sua maioria, totalizando um percentual de 54\% (14) afirmou concordar totalmente; $38 \%$ (10) concordaram parcialmente; não havendo discordância parcial ou total; e, apenas 2 respondentes representando um percentual de $8 \%$, não concordaram nem discordaram da assertiva.

De acordo com os respondentes, foi perceptível à relevância que o processo de ensino e aprendizagem da ética profissional traz para o exercício profissional, um dos respondentes deixou isto de forma clara, afirmando: "este processo leva o aluno a buscar uma reflexão mais profunda e a se questionar o que de fato vale a pena. É importante ressaltar que a ética tem inteira ligação com o caráter e isso se torna algo pessoal, por cada um pensar e agir de maneiras distintas".

Seguindo a mesma linha de raciocínio, foi dada a seguinte afirmação: "Saber e compreender a ética na profissão contábil nos auxiliará em nossa conduta no mercado de trabalho". Quanto aos que concordaram parcialmente foi afirmado que: "o ensino é de grande valor, mas, sempre existem profissionais que se deixam corromper".

Percebe-se, diante das justificativas dos discentes que é de grande contribuição para a conduta profissional a compreensão da ética, gerando reflexos positivos através do ensino de qualidade para termos um bom desempenho profissional, porém, existem profissionais que deixam a desejar.

A segunda questão destina-se a abordar a percepção do respondente sobre a contribuição do processo de ensino e aprendizagem quanto à formação crítica do discente. $\mathrm{O}$ 
questionamento foi apresentado da seguinte forma: Qual sua percepção sobre a contribuição do processo de ensino e aprendizagem na formação crítica do discente relativo ao exercício dos princípios éticos na profissão contábil?

Um percentual de 50\% (13 respondentes) apresentou concordância parcial; e, 15\% (4) concordaram totalmente, em contraponto, 4\% (1 respondente) discordou totalmente; e um percentual de $8 \%$ ( 2 respondentes) discordou parcialmente; e, $23 \%$ o equivalente a 6 respondentes não concordaram nem discordaram com a assertiva.

Quanto aos que concordaram parcialmente, um dos respondentes afirmou o seguinte: "resulta sim, mas, cada um tem sua forma de agir e não será uma aprendizagem que mudará uma pessoa antiética". Outro respondente afirma: "a ética ajuda a seguir o caminho correto da atividade".

Portanto, é visto com base na percepção dos discentes que o processo de ensino e aprendizagem da ética na contabilidade quanto à sua aplicação no exercício da profissão contábil é de grande valor, tendo em vista que este processo contribui de forma enriquecedora para a formação crítica dos discentes.

A seção seguinte procurou identificar a opinião do respondente, com relação às formas de ensino, alternativas que estimulem o discente ao aprendizado, indagando a seguinte questão: Com relação ao processo de ensino da Ética Profissional, você compreende que o professor deve sempre estar buscando formas de ensino e alternativas que estimulem o discente ao aprendizado?

Foi apresentado pelos respondentes com um percentual de $85 \%$ (22) concordância total com o questionamento exposto; $8 \%$ ( 2 respondentes) concordam parcialmente; quando observados os elementos "discordo parcialmente" e "não concordo nem discordo" foram obtidos os mesmos percentuais, 4\% (1 respondente), cada, não havendo discordância total.

Um dos respondentes que concordou parcialmente afirmou: "O educando tem por obrigação buscar fontes para novos conhecimentos, não é obrigação apenas do professor”.

Posteriormente, um dos respondentes que concordou totalmente, afirmou: "estimular o discente é fator primordial para sua formação, desta forma, ele terá ciência do seu compromisso; outro respondente segue a mesma linha de pensamento afirmando: 'a dinamização das aulas ajuda na compreensão do assunto"”.

Tornando-se assim perceptível que o professor deve criar condições de ensino que atendam às características de aprendizagem dos discentes, devendo o aluno também contribuir para que este processo de ensino e aprendizagem seja feito de maneira satisfatória para ambas as partes.

A última questão relacionada à percepção dos alunos acerca do ensino da Ética Profissional em Contabilidade deu-se pela seguinte indagação: Quanto ao ensino da Ética Profissional, você considera que o atual modelo de ensino contribui para o conhecimento $e$ futura aplicação dos princípios éticos enquanto profissional?

Apenas 1 respondente com percentual de 4\% discorda parcialmente. Representando um percentual de $15 \%, 4$ dos respondentes não concordaram nem discordaram; concordaram parcialmente $46 \%$, o equivalente a 12 respondentes; e, 9 concordaram totalmente representando um percentual de $35 \%$.

Dos que concordaram parcialmente foi afirmado o seguinte: "o ensino atual contribui sim, isso é inquestionável, mas, deveria ter mais planejamento e incentivos tanto por parte do 
professor como da instituição de ensino", outro respondente seguindo a mesma linha de raciocínio também afirmou: "a aplicabilidade ainda difere da teoria".

O único respondente que discordou parcialmente relatou o seguinte: "A ética também vem do caráter humano não só através do ensino". Percebe-se diante da afirmação que a ética também é algo que nos é dado por influência do meio e não algo que possa ser desenvolvido e aprendido somente de uma hora para outra em sala de aula.

Neste bloco, as respostas indicam que o processo de ensino e aprendizagem é de grande influência e contribuição para o exercício profissional, mas nem sempre corresponde às expectativas dos discentes, deixando algo a desejar.

A percepção dos respondentes indica que o processo de ensino deve ser alvo de constantes renovações, pois este sofre a influência tanto dos docentes quanto dos discentes, sendo, portanto, um processo que traz uma reflexão crítica sobre a ética quando desempenharem o exercício prático da profissão contábil.

\section{CONCLUSÃO}

Este estudo buscou compreender a percepção dos alunos do curso de Ciências Contábeis da Faculdade de Ciências Aplicadas do Limoeiro - FACAL, no que diz respeito à aplicação dos conceitos éticos na profissão contábil, e, ao processo de ensino da Ética aplicada a Contabilidade.

Para tanto, foi elaborado um questionário cujo objetivo era identificar a percepção dos alunos do curso de Ciências Contábeis acerca da aplicação dos conceitos de Ética profíssional e sobre o processo de ensino e aprendizagem da ética na contabilidade.

A população de pesquisa correspondeu aos alunos do $5^{\circ}$ ao $8^{\circ}$ semestre do curso de Ciências Contábeis da Faculdade de Ciências Aplicadas de Limoeiro (FACAL). Dessa forma, a população de pesquisa compreendeu todos os alunos dos semestres acima citados, totalizando 52 alunos.

Após a aplicação dos questionários, foram excluídos aqueles onde os respondentes não responderam todas as perguntas, totalizando dessa forma uma amostra de 26 questionários analisados por essa pesquisa, sendo reduzida quantidade de alunos matriculados neste semestre letivo e, consequentemente, dos respondentes, uma limitação deste estudo.

Quanto ao tratamento dos dados coletados através do questionário, sua análise foi feita através de duas técnicas: a estatística descritiva e a análise de conteúdo. Sendo possível perceber que, diante da percepção dos discentes, a ética é considerada fator de grande importância no ambiente profissional, mas, também, encontram limitações na aplicação dos princípios do código de ética, sendo um procedimento de difícil aplicação.

Quanto ao processo de ensino, é considerado um meio facilitador que contribui de forma enriquecedora para a formação crítica do discente, devendo ser alvo de constantes renovações, pois este sofre a influência tanto dos docentes quanto dos discentes, sendo, portanto, um processo que traz aos discentes uma reflexão crítica sobre a ética quando desempenharem o exercício prático da profissão contábil.

Como sugestão para pesquisas futuras, sugere-se desenvolver este estudo em outras instituições de ensino superior para uma análise da percepção dos alunos acerca da aplicação de conceitos éticos na profissão contábil e, sobre o processo de ensino da ética na contabilidade, tendo em vista, que os atuais alunos serão os futuros profissionais da área contábil. 


\section{REFERÊNCIAS}

ANTONOVZ, Tatiane; ESPEJO; Márcia Maria B.; STEINER NETO, Pedro José; VOESE, Simone Bernardes. Atitudes éticas dos contadores: evidências recentes de uma pesquisa com alunos e profissionais contábeis sob perspectiva de gênero. RCO - Revista de Contabilidade e Organizações - FEA-RP/USP, v. 4, n. 10, p. 89-105, set-dez 2010.

ASSAF NETO, Alexandre. ARAÚJO, Adriana Maria Procópio de. Introdução a Contabilidade. São Paulo: Atlas, 2004.

BORGES, Erivan Ferreira; MEDEIROS, Carlos Alberto Freire. Preceitos e regras éticas: como se dá a introjeção de preceitos éticos por contadores e técnicos em contabilidade na sua atuação profissional. Revista Contabilidade Vista \& Revista, v. 18, n.2., p. 49-72, abr./jun. 2007.

COVA, Carlos José Guimarães. A contabilidade e a ética: os imperativos para o crescimento econômico do brasil. Pensar Contábil, Rio de Janeiro, v. 6, n. 26, 2005.

CUNHA, Patrícia Vasconcelos Boavista da. Contabilidade, ética e espaço público. Pensar Contábil, Rio de Janeiro, v. 7, n. 29, 2005.

FREIRE, Paulo. Pedagogia do oprimido. Rio de Janeiro: Paz e Terra, 1987.

LISBOA, Lázaro Plácido. Ética Geral e Profissional em Contabilidade. São Paulo: Atlas, 1997.

LUSTOSA, Paulo Roberto Barbosa; DANTAS, José Alves; FERNANDES, Bruno Vinícius Ramos; SILVA, José Dionísio Gomes da. A moral do contador brasileiro: uma avaliação por meio da escala ética multidimensional. Revista Contabilidade Vista \& Revista, v. 23, n. 1, p. 15-45, jan./mar. 2012.

MARION, José Carlos. O ensino da contabilidade. $2^{\text {a }}$ ed. São Paulo Atlas, 2001.

Contabilidade Básica. 10ª ed. São Paulo:Atlas, 2009

MENDES, João Batista. Utilização de jogos de empresas no ensino de contabilidade - Uma experiência no curso de Ciências Contábeis da Universidade Federal de Uberlândia. Contabilidade Vista e Revista, Belo Horizonte, v. 11, n. 3, p 23-41, dez. 2000.

MORAES, Melissa Christina Corrêa de; SILVA, Aline Moura Costa da; CARVALHO, Frederico Antonio Azevedo de. O comportamento dos futuros contabilistas perante diferentes dilemas éticos. Pensar Contábil, Rio de Janeiro, v. 12, n. 48, p. 22 - 30, maio/ago. 2010.

SÁ, Antonio Lopes de. Ética Profissional. $4^{\mathrm{a}}$ ed. São Paulo: Atlas, 2001.

SALLABERRY, Jonatas Dutra; SALLABERRY, Bárbara Rocha Bittencourt. A acessibilidade sob o enfoque ético na contabilidade. Revista Ambiente Contábil - UFRN Natal-RN. v. 4. n. 1, p. 89 - 105, jan./jun. 2012.

SANTOS, Roberto Vatan dos. Jogos de Empresas. Aplicados ao Processo de Ensino e Aprendizagem de Contabilidade. Revista Contabilidade e Finanças - USP, São Paulo, n 31, p. 78-95, janeiro/abril, 2003.

VALLS, Álvaro L. M. O QUE É ÉTICA.9ª ed. São Paulo: Brasiliense, 1994. 